\title{
ANALISIS MAKNA TANDA PADA FILM KARTINI : RESISTENSI PEREMPUAN JAWA TERHADAP BUDAYA PATRIARKI
}

\author{
Nurudin Sidiq Mustofa \\ Siti Maemunah \\ Lilik Kustanto
}

Jurusan Film \& Televisi, Fakultas Seni Media Rekam, Institut Seni Indonesia Yogyakarta Jl. Parangtritis km. 6.5 Yogyakarta Telp. (0274) 381047

\begin{abstract}
The term patriarchy is used to refer to "male power" specifically the power in which male domination of women occurs which is realized in various ways. Men are considered to have more power than women so that people view women as weak and helpless. However, with the participation of women who echoed the spirit of movement in countering the injustice of patriarchal culture, this social change was taken by the media to be socialized through propagation media that focused visual auditivity, for example in films. The paper thesis was intended to look for signs of resistance (resistance) to patriarchal culture in the components of the film

This research is a qualitative research with qualitative descriptive method, namely by conducting research on signs of resistance against patriarchal culture on the components of Kartini's film. The analysis unit to be used is the scene. The results of the research data are processed by qualitative analysis which is encoded by the three-level theory of social code proposed by John Fiske so that conclusions can be drawn.

Based on the results of the study it can be concluded that some film components show signs of resistance to culture such as wardrobe, movement, sound, music, editing, arrangement, and cinematography. These signs after coding are done using the Three levels of the Social Code showing women's representation of the culture of the Patriarchy.
\end{abstract}

Keywords: Resistance, Women, Patriarchal Culture, Signs, Film Components

ABSTRAK

Istilah patriarki digunakan untuk menyebut "kekuasan laki-laki" khususnya kekuasan yang didalamnya berlangsung dominasi laki-laki atas perempuan yang direalisasikan melalui berbagai cara. Laki-laki dianggap memiliki kekuatan lebih dibanding perempuan sehingga masyarakat memandang perempuan sebagai seorang yang lemah dan tidak berdaya. Namun seiring dengan banyaknya perempuan yang mendengungkan semangat pergerakan dalam melawan ketidakadilan budaya patriarki, gejala sosial ini ditangkap oleh media untuk disosialisasikan kedalam proyeksi media yang bersifat auditif visual, contohnya pada film. Skripsi karya tulis berjudul "R esistensi Perempuan Jawa Terhadap Patriarki (Analisis Makna Tanda Pada Film Kartini)" ini bertujuan untuk mencari tanda-tanda resistensi (perlawanan) terhadap budaya patriarki didalam komponen-komponen film.

Penelitian ini merupakan penelitian kualitatif dengan metode deskriptif kualitatif, yaitu dengan melakukan pencarian tanda-tanda resistensi (perlawanan) terhadap budaya patriarki pada komponen-komponen film Kartini. Unit analisis yang akan digunakan adalah scene. Data hasil penelitian diolah dengan analisis kualitiatif yang dikodekan dengan teori three level of social codes yang dikemukakan oleh John Fiske sehingga bisa ditarik beberapa kesimpulan.

Berdasarkan hasil kajian dapat disimpulkan bahwa beberapa komponen- komponen film menunjukan tanda-tanda resistensi (perlawanan) terhadap budaya patriarki seperti wardrobe, pergerakan, sound, musik, editing, setting, dan sinematografi. Tanda-tanda tersebut setelah dilakukan pengkodean menggunakan Three level of Social Codes menunjukan representasi perlawanan perempuan Jawa terhadap budaya Patriarki.

Kata Kunci : Resistensi, Perempuan, Budaya Patriarki, Tanda, Komponen Film 


\section{Pendahuluan}

Citra perempuan Jawa erat kaitannya dengan tata krama yang menyertainya. Pandangan bahwa perempuan haruslah menjadi seorang penurut, setia, serta lembut telah tertanam dalam kehidupan bermasyarakat di tanah Jawa. Budaya dan tata nilai dalam masyarakat yang telah dibentuk sedemikian rupa, membuat terjadinya pembagian peran antara kaum laki-laki dan kaum perempuan dimana peran publik dimainkan oleh laki-laki sedangkan peran domestik dimainkan oleh perempuan. Peran publik yang dimainkan oleh laki-laki menghasilkan materi maupun kedudukan yang membuatnya mendapatkan posisi superior. Sedangkan peran perempuan yang tidak menghasilkan materi maupun kedudukan membuatnya diletakkan pada posisi inferior.

Penggolongan superior dan inferior tersebutlah yang menyebabkan sebagian lakilaki memandang rendah status perempuan sebagai ibu rumah tangga. Tugas perempuan yang terbatas pada wilayah domestik kerap dipandang sebelah mata. Cara pandang tersebut yang menyebabkan status ibu rumah tangga menjadi semakin dianggap remeh. Warisan budaya yang dipelihara dalam masyarakat, sering memosisikan perempuan sebagai pelengkap sehingga membuat perempuan takut untuk menyuarakan hak-hak yang sepatutnya didapatkan oleh perempuan. Pemikiran- pemikiran seperti itulah yang menyebabkan patriarki tumbuh subur di tanah Jawa.

Seiring dengan banyaknya perempuan yang mendengungkan semangat pergerakan dalam melawan ketidakadilan budaya patriarki, gejala sosial ini ditangkap oleh media untuk disosialisasikan ke dalam proyeksi media yang bersifat auditif visual, contohnya pada film. Film merupakan jenis kesenian yang paling muda sebelum ada televisi karena televisi itu sendiri pada dasarnya adalah film, yakni gambar bergerak yang ditonton di layar (Damono, 2012:91). Film dianggap sebagai agen perubahan sosial, setidaknya membantu semangat kesetaraan gender sehingga perempuan dapat menentukan dan mengekspresikan keinginan dalam hidupnya.

Tahun 2017, dirilis sebuah film fiksi ber-genre drama yang berjudul "Kartini" yang disutradarai oleh Hanung Bramantyo. Film yang mengisahkan tentang Raden Ajeng Kartini yang lahir di Mayong, Jepara tanggal 21 April 1879. Di awal tahun

1900, saat Indonesia masih dijajah Belanda, Pulau Jawa dipimpin oleh para ningrat dengan pengawasan dari pemerintah Belanda. Saat itu hanya putra keturunan ningrat yang boleh bersekolah dan mengenyam pendidikan, sedangkan wanita tetap tidak diperbolehkan mendapat pendidikan yang tinggi. Wanita Jawa hanya boleh memiliki satu tujuan hidup, yaitu menjadi istri. Kartini berjuang bersama kedua 
adiknya, Roekmini dan Kardinah untuk memperjuangkan kesetaraan hak bagi semua orang, yaitu hak pendidikan terutama bagi perempuan. Kartini dan adik-adiknya membuat sekolah untuk kaum miskin dan menciptakan lapangan kerja untuk rakyat di Jepara dan sekitarnya. Kartini mendobrak budaya patriarki yang mengalir dengan kental pada budaya Jawa.

Film Kartini akan dikaji menggunakan metode semiotika John Fiske untuk membongkar dan mendeskripsikan bagaimana tanda- tanda perlawanan dan budaya patriarki terbentuk melalui komponen film. Semiotika John Fiske dipilih karena adanya kesamaan antara alat untuk mengukur tanda-tanda tersebut dengan teori komponen film oleh Maria Pramaggiore dan Tom Wallis pada buku Film: a Critical Introduction. Pada unsur film naratif terdapat komponen setting yang mirip dengan environment atau lingkungan di level realitas pada tiga level kode sosial semiotika John Fiske. Contoh lain pada komponen mise-en-scene atau sinematik pada komponen pembentuk film terdapat komponen setting, tata cahaya, kostum dan make up, akting dan pergerakan pemain sama dengan penampilan (appearance), kostum (dress) dan make up pemain, perilaku, ucapan, gestur, ekspresi, dialog di level realitas. Terdapat pula komponen film editing dan suara yang sama dengan level representasi pada teori three level of social codes John Fiske.
Metode pengambilan data yang akan digunakan dalam penelitian adalah metode dokumentasi. Metode dokumentasi adalah mencari data mengenai variabel-variabel yang berupa benda mati seperti catatan, transkrip, buku, surat kabar, majalah, prasasti, film, dan lain-lain. Sumber data dalam penelitian ini berupa sebuah film yang berjudul "Kartini" yang diambil dari $D V D$ film tersebut.

Penelitian ini menggunakan analisis data kualitatif yaitu penelitian yang bekerja dengan data, mengorganisasi, memilahmilah, mensintesiskan, mencari, dan menemukan pola, menemukan apa yang penting dan apa yang dipelajari, serta memutuskan apa yang dapat diceritakan kepada orang lain (Moloeng, 2007:248). Analisis data kualitatif dilakukan dengan pendekatan deskriptif yaitu penelitian yang menuturkan, menganalisa, dan mengklasifikasi (dengan teknik survey, interview, angket, observasi, tes) studi kasus (Surakhmad, 1990: 139).

Penelitian kualitatif deskriptif ini kemudian dianalisa dan interpretasi secara mendalam dari data-data yang telah dideskripsikan yang bertujuan untuk memaknai data- data sesuai dengan teori yang digunakan.

\section{Pembahasan}

Resistensi berasal dari bahasa Inggris yaitu resist yang dapat berarti perlawanan. Perlawanan yang dimaksud adalah tindakan 
yang menolak atau melawan dan bertahan.

Sementara resistensi dalam sosiologi adalah suatu perlawanan yang dilakukan secara terang-terangan ataupun diam-diam atas kebijakan maupun aktivitas yang dilakukan dalam suatu pihak di dalam masyarakat.

Teori resistensi akan digunakan sebagai parameter dalam melihat jenis-jenis perlawanan pada tanda- tanda yang terkandung pada komponen-komponen film Kartini. Bentuk perlawanan menurut Scott (Scott, 1990:198) :

1. Publik Declared Resistance yaitu resistensi terbuka.

Resistensi ini berbentuk :
a. Petisi
b. Demonstrasi.
c. Boikot.
d. Pemogokan.
e. Invasi tanah.
f. Pemberontakan publik.
g. Pernyataan publik tentang nilai dengan isyarat (gestur), pakaian, pidato.

h. Penodaan terbuka terhadap simbol status yang dominan.

i. Ideologi tandingan yang mempublikasikan persamaan.

\section{j. Revolusi}

k. Meniadakan ideologi yang berkuasa.

2. Disguised, Low Profile, Undisclosed Resistance, merupakan bentuk resistensi yang tertutup bersifat rahasia dan low profile. Resistensi ini dapat berbentuk : a. Bentuk perlawanan sehari- hari (everyday forms of resistance) seperti perburuan, jongkok, desersi, penggelapan, menyeret kaki.

b. Resistensi langsung oleh penentang terselubung seperti derma terselubung, ancaman, ancaman anonim.

c. Transkrip kemarahan yang tersembunyi.

d. Agresi.

e. Wacana kewibawaan yang disamarkan seperti ritual agresi, dongeng balas dendam, penggunaan simbolisme karnaval, gosip, desasdesus, penciptaan ruang sosial yang otonom untuk penegasan martabat.

f. Pengembangan sub budaya yang tidak sepakat seperti agama milenial, budak "hush-arbors", agama rakyat, mitos banditisme sosial dan pahlawan kelas, dunia citra terbalik, mitos raja yang baik pada masa itu sebelum "Norman Yoke".

Sementara itu patriarki secara harfiah berarti kekuasaan bapak atau patriarch. Mulanya patriarki digunakan untuk menyebut suatu jenis "keluarga yang dikuasai oleh kaum laki-laki”, yaitu rumah tangga besar patriarch yang terdiri dari kaum perempuan, laki-laki muda, anak- anak, budak, dan pelayan rumah tangga yang semuanya berada di bawah kekuasaan lakilaki penguasa itu. Sekarang istilah ini 
digunakan secara lebih umum untuk menyebut kekuasaan laki-laki (Bhasin, 1996:1).

Menurut Kamla Bhasin dalam bukunya Menggugat Patriarki, ada beberapa bidang kehidupan yang dikontrol oleh laki-laki terkait dengan budaya patriarki antara lain daya produktif atau tenaga kerja perempuan, reproduksi perempuan, kontrol atas seksualitas perempuan, gerak perempuan, dan harta dan sumber daya ekonomi lainnya.

Pengkode yang digunakan dalam penelitian ini menggunakan teori three level of social codes milik John Fiske. Tandatanda berasal dari komponen-komponen yang terdiri dari naratif, mise-en-scene, sinematografi, suara, dan editing ini dimasukan kedalam tiga level kode sosial yang terdiri dari level realitas, level representasi, dan level ideologi. Level ideologi berisi penampilan (appearance), pakaian (dress) dan make up yang digunakan oleh pemain, lingkungan, perilaku, ucapan, gestur, ekspresi, dialog dan sebagainya yang dipahami sebagai kode budaya yang ditangkap secara elektronik melalui kode-kode teknis. Sementara Level Representasi dapat berupa kerja kamera, pencahayaan, editing, musik dan suara, yang ditransmisikan sebagai kode-kode representasi yang bersifat konvensional. Level ideologi meliputi semua ideologi yang terkandung pada film atau program televisi ideologi. Beberapa contoh ideologi seperti (coherence) dan penerimaan sosial (social acceptability) seperti individualism, class (kelas), patriarchy (patriarki), gender, race (ras), materialsm (materialisme), capitalsm (kapitalisme), liberalism (liberalisme), dan sebagainya.

Unit analisis yang digunakan adalah scene-scene dari film Kartini. Pengambilan sampel dilakukan dengan melihat tanda-tanda resistensi terhadap budaya patriarki pada komponen-komponen film Kartini. Tidak semua komponen-komponen tersebut masuk dalam pembahasan, hanya komponenkomponen yang menunjukan tanda-tanda resistensi terhadap budaya patriarki yang akan dianalisis. Tanda-tanda yang nampak pada komponen-komponen film Kartini kemudian dimasukan dalam pengkodean tiga level sosial John Fiske untuk melihat seperti apa tanda- tanda tersebut bekerja.

\section{Resistensi Tertutup (Agresi) terhadap Pembatasan Gerak \\ Perempuan (Scene 2)}

\section{a. Level Realitas}

\section{1) Setting (Enviroment)}

Setting berada di pendopo tempat Kartini dan keluarganya terjadi yaitu di Kadipaten Japara. Pembatasan yang dilakukan yaitu larangan dari Kartini untuk tidur bersama ibu kandungnya di kamar yang berada di area gandhok. Larangan tersebut dilakukan karena sebagai anak ningrat, Kartini harus tidur bersama keluarganya di dalem ageng karena dalem ageng dianggap 
sakral bagi keluarga utama, sementara ibunya yang merupakan selir (garwa ampil) tidak memiliki ruang atau tempat di dalam dalem ageng karena memiliki status sosial yang lebih rendah dibanding RA Moeryam yang merupakan garwa padma dari RM Soesroningrat, namun anak dari garwa ampil memiliki hak yang sama dengan anak garwa padma sehingga pembatasan tersebut dilakukan kepada Kartini agar tidak tidur di gandhok bersama ibu kandungnya.

\section{2) Wardrobe}

Warna wardrobe yang digunakan karakter pada scene 2 film Kartini melambangkan beberapa hal. Pada karakter Kartini kecil, pakaian yang digunakan adalah jarik dan kebaya berwarna putih. Warna putih adalah warna netral dan seringkali diasosiasikan dengan kesucian dan keluguan. Menunjukan posisi Kartini di scene tersebut sebagai pihak yang tidak memiliki kuasa. Selain itu, Kartini merupakan anak dari garwa ampil. Anak dari garwa padma dianggap lebih tinggi derajatnya daripada anak garwa ampil, sehingga Kartini tidak memiliki kuasa pada keluarga tersebut.

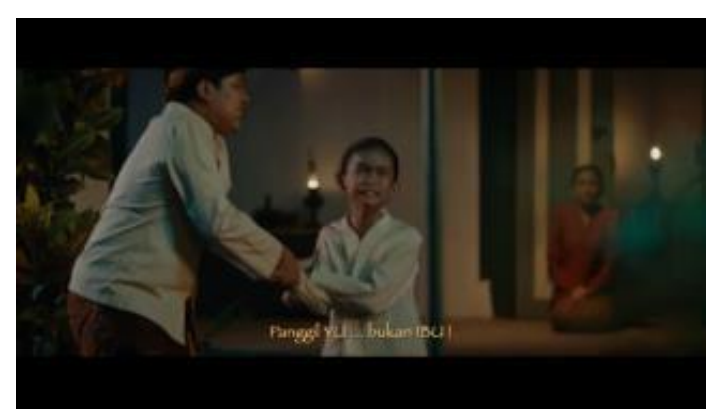

Sementara R.M Sosroningrat dan R.A. Moeryam masing-masing menggunakan beskap dan kebaya warna hijau. Hijau adalah warna yang sangat dikotomis. Hijau adalah warna sayuran segar dan daging yang busuk. Warna hijau pada tanaman dapat memberi sinyal kehidupan. Tetapi hijau pada atmosifr dapat memberikan tanda tekanan rendah pada atmosfir yang dapat menyebabkan tornado, dan "waspada air hijau" bagi pelaut merupakan tanda bahaya. Jadi hijau dapat menandakan ketentraman dan kehidupan atau bahaya dan pembusukan. (Belantoni, 2005:160). Warna hijau yang digunakan RM Sosroningrat atau ayah Kartini melambangkan kedamaian dan pengayoman dari sosok seorang ayah. Sementara warna hijau yang digunakan RM Moeryam atau Ibu Tiri Kartini melambangkan bahaya dan kerusakan. RM Moeryam merupakan garwa padmi atau istri utama dari seorang ningrat atau pejabat. Kedudukan sosial garwa padma lebih tinggi dari istri-istri lainnya (garwa ampil) sehingga RM Moeryam merasa memiliki kuasa atas Kartini yang merupakan anak garwa ampil.

Di sisi lain, Yu Ngasirah memakai kebaya berwarna merah terang. Belatoni menyebutkan bahwa penggunaan warna merah dapat membuat efek kecemasan secara terus menerus (Belantoni, 2005:20). Warna merah yang dipakai Yu 
Ngasirah melambangkan kecemasan yang dialami olehnya karena kedudukannya di lingkungan sosial tersebut. Selain itu, warna merah juga dapat menyimbolkan cinta (Morton, 1997:23). Pada scene tersebut, Yu Ngasirah adalah ibu kandung kartini dan dapat menyimbolkan kasih sayang Yu Ngasirah ke Kartini.

\section{3) Behaviour}

Beberapa perilaku yang dilakukan karakter pada scene 12 mengarah kepada perilaku agresi yang dilakukan untuk menentang kuasa patriarki yang diterapkan pada lingkungan tersebut. Terlihat pada adegan Kartini yang ingin tidur di kamar ibu kandungnya ditarik paksa oleh kedua kakak lelakinya tetapi Kartini menolak dan menggigit kakaknya Busono. Pemaksaan yang dilakukan kakak lelakinya menunjukan dominasi laki- laki atas perempuan dalam bentuk pembatasan gerak perempuan. Kemudian perilaku Kartini yang menolak dan menggigit kakak lelakinya menunjukan agresi atas kuasa kakaknya.

\section{b. Level Representasi}

\section{1) Suara (Dialog)}

Busono : "Ayo!"

Kartini : "Tidak Mau!”

Slamet : "Panggil Yu, bukan Ibu!"

Kartini : "Tidak Mau, Yu ngasirah

bukan Pembantu!"

Slamet: "Sekarang kamu anak bupati, bukan wedana lagi.
Sekarang tidur dirumah. Busono!

Bawa dia Pergi!"

Busono : "Kurang ajar! Dia menggigit!"

Dialog yang dilakukan antara Kakak lelaki Kartini dan Kartini menunjukan pemaksaan yang dilakukan oleh mereka dan agresi yang dilakukan oleh Kartini. Pemaksaan yang dilakukan berupa pembatasan gerak perempuan dan dominasi laki-laki di dalam keluarga. Selain itu menunjukan strata sosial yang ada di lingkungan tersebut.

\section{2) Kamera}

Teknik rack focus atau memindah fokus digunakan untuk memindah fokus dari Busono ke Kartini. Fokus dipindahkan untuk memperlihatkan ekspresi kemarahan Kartini.

\section{c. Level Ideologi}

Dari realitas dan representasi yang telah dijabarkan, ideologi yang terkandung pada scene 2 menunjukan resistensi tertutup berupa agresi terhadap budaya patriarki yaitu pembatasan gerak perempuan. Agresi dilakukan oleh Kartini atas pembatasan gerak perempuan yang dilakukan oleh kakak lelakinya. Agresi tersebut berupa kemarahan, teriakan, dan kontak fisik kepada kakak lelakinya. Dan pembatasan gerak yang dilakukan oleh kakak Kartini adalah larangan untuk tidur di kamar ibu kandungnya. Tanda-tanda yang menunjukan agresi terhadap pembatasan gerak perempuan berupa environment atau 
setting, wardrobe atau dress dan behavior atau pergerakan pada level realitas serta suara (dialog) dan sinematografi pada level representasi.

Di dalam film ini terdapat 12 scene yang mengandung unsur resistensi (perlawanan) terhadap budaya patriarki yang bisa dilihat dari tiga level pengkodean John Fiske, yaitu level realita (reality), level representasi (representation), dan juga ideologi (ideology).

\section{Kesimpulan}

Setelah menganalisis tanda- tanda pada komponen-komponen film, maka dapat disimpulkan bahwa di dalam film Kartini terdapat tanda-tanda perlawanan perempuan Jawa terhadap budaya patriarki. Beberapa unsur pembentuk film yang menunjukan tanda-tanda perlawanan budaya patriarki antara lain setting, sinematografi, mise-enscene, editing, dan suara. Tanda-tanda pada film Kartini bekerja melalui komponenkomponen film yang terdapat pada film Kartini mulai dari setting, sinematografi, mise-en-scene, editing, dan suara.

Ditemukan tujuh bentuk resistensi tertutup dan satu bentuk resistensi terbuka berupa agresi, wacana kewibawaan yang disamarkan yaitu penciptaan ruang sosial yang otonom untuk penegasan martabat, transkrip kemarahan yang tersembunyi, pernyataan publik tentang nilai dengan pidato, pengembangan subbudaya tidak sepakat berupa mitos banditisme dan pahlawan kelas, wacana kewibawaan yang disamarkan berupa gosip, dan ideologi tandingan yang mempublikasikan persamaan. Unsur-unsur resistensi terhadap budaya patriarki meliputi antara lain:

1. Resistensi tertutup (Agresi) terhadap budaya patriarki (Pembatasan Gerak Perempuan) yang terdapat di scene 2.

2. Resistensi tertutup (wacana kewibawaan yang disamarkan yaitu penciptaan ruang sosial yang otonom untuk penegasan martabat) terhadap budaya patriarki (pembatasan gerak perempuan) pada scene 11 dan 12.

3. Resistensi tertutup (transkrip kemarahan yang tersembunyi) terhadap budaya patriarki (pembatasan gerak perempuan) pada scene $28,29,30,31,32$.

4. Resistensi terbuka (pernyataan publik tentang nilai dengan pidato) terhadap budaya patriarki (pembatasan gerak perempuan) pada scene 33.

5. Resistensi tertutup (pengembangan subbudaya yang tidak sepakat berupa mitos banditisme dan pahlawan kelas) terhadap budaya patriarki (daya produktif perempuan) pada scene 39.

6. Resistensi tertutup (wacana kewibawaan yang disamarkan yaitu gosip) terhadap budaya patriarki 
(kontrol atas reproduksi perempuan) pada scene 40 .

7. Resistensi tertutup (ideologi tandingan yang mempublikasikan persamaan) terhadap budaya patriarki (kontrol atas seksualitas perempuan) pada scene 64.

Berdasarkan analisis yang telah dilakukan pada bab sebelumnya, maka dapat ditarik kesimpulan dari penelitian ini bahwa tanda-tanda dalam komponenkomponen film Kartini merepresentasikan perlawanan perempuan jawa terhadap patriarki. Perlawanan perempuan jawa terhadap patriarki terrepresentasikan melalui tanda- tanda pada komponen-komponen film. Tanda tersebut berupa setting, mise-enscene, sinematografi, editing, dan suara.

\section{Daftar Pustaka}

Belantoni, Patti. If it's purple someone's gonna die: The power of color in visual storytelling. Singapore : Elsevier, 2005.

Bhasin, Kamla. Menggugat Patriarki. Yogyakarta : Yayasan Bentang

Bordwell, David, dan Kristin Thompson. Film Art: an Introduction. Boston: McGraw Hill, 2008.

Djaya, Kusuma Ashad dan Ki Guno Asmoro. Asmaragama Wanita Jawa : Spiritualitas dan Pesona
Seksualitas dalam Kearifan Tradisional. Yogyakarta : Kreasi Wacana, 2004.

Fiske, John. Cultural and Communication Studies: Sebuah Pengantar Paling Komprehensif. Yogyakarta : Jalasutra, 2004.

Fiske, John. Pengantar Ilmu Komunikasi Edisi Ketiga. Jakarta : Rajawali Pers, 2016.

Handayani, Christina J., dan Ardhian Novianto. Kuasa Wanita Jawa. Yogyakarta : LKIS, 2004.

Junaedi, Deni. Estetika Jalinan Subjek, Objek, dan Nilai. Yogyakarta : Badan Penerbit ISI Yogyakarta, 2013.

Koentjaraningrat. Kebudayaan Jawa. Jakarta : Balai Pustaka, 1994.

Kristiyanto, Eddy. Sinar Sabda Dalam Prisma. Yogyakarta : Kanisius, 2005.

Millet, Kate. Sexual Politics. Illinois: University of Illinois Press, 2000. http://webruhan.files.wordpre ss.com/millet. Juga tersedia dalam bentuk cetak

Moloeng, Lexy J. Metodologi Penelitian Kualitatif Edisi Revisi. Bandung: PT Remaja Rosdakarya, 2007.

Morton, Jill. A guide to color symbolism. Colorcom, 1997.

Mulyana, Deddy. Ilmu Komunikasi : Suatu Pengantar. Bandung: Rosda, 2017. 
Nastiti, Titi Surti. Perempuan Jawa Kedudukan dan Peranannya dalam Masyarakat Abad VIII- XV. Jakarta : Pustaka Jaya, 2016.

Nelmes, Jill. An Introduction to Film Studies. London : Routledge, 1996. Pramaggiore, Maria, dan Tom Walls. Film a Critical Introduction. London : Laurence King, 2011.

Pratista, Himawan. Memahami Film Edisi 2. Yogyakarta : Montase Press, 2016. Scott, James C. Domination and the Arts of Resistence. New Haven and London : Yale University Press, 1990.

Sobur, Alex. Semiotika Komunikasi. Bandung : Rosda, 2017.

Soeroto, Sitisoemandari. Kartini Sebuah Biografi. Jakarta : Gunung Agung, 2001.

Surakhmad, Winarno. Pengantar Penelitian Ilmiah dasar Metoda Teknik. Bandung: Tarsito, 1990.

Suseno, Franz Magnus. Etika Jawa : Sebuah Analisa Falsafi Tentang Kebijakan Hidup Jawa. Jakarta : Gramedia, 1985.

Vera, Nawiroh. Semiotika dalam Riset Komunikasi. Bogor : Ghalia Indonesia, 2014.

Asmarani, Ratna. "Perempuan Dalam Perspektif Kebudayaan:. Skripsi S1 Fakultas Ilmu Budaya Universitas Diponegoro, 2017.
Brahmana, Neni Munthi Rima Sembiring. "Perlawanan Perempuan Batak Terhadap Budaya Patriarki Dalm Film 'Tiga Nafas Likas' (Analisis Naratif Film)". Skripsi S1 Institut Seni Indonesia Yogyakarta, 2017.

Dianingtyas, Edwinda Ayu. "Representasi Perempuan Jawa dalam Film R.A. Kartini". Jurnal Ilmu Sosial dan Ilmu Politik Universitas Negeri Semarang, 2010.

Hermawati, Tanti. "Budaya Jawa dan Kesetaraan Gender". Jurnal Komunikasi Massa Fakultas Ilmu Sosial Ilmu Politik Universitas Sebelas Maret Vol. 1, No.1, 2007. Iqbal, Muhammad. "Postmodernisme dalam Film Village of The Watermills". Jurnal Ilmu Komunikasi dan Politik Universitas Islam Bandung, 2015. Khotimah, Anisa Khusnul. "Perlawanan Kaum Perempuan Terhadap Patriarki dalam Film." Skrip s1 Universitas Negeri Sebelas Maret, 2010.

Kurnia, Novi. "Representasi Maskulinitas Dalam Iklan”. Jurnal Ilmu Sosial dan Ilmu Politik Universitas Gadjah Mada, Vol. 8, No.1., 2004. Kusuma, Titisari. "Patriarki Dalam Kebudayaan Jawa (Studi Semiotik Simbol-Simbol dalam Prosesi Pernikahan Adat Jawa)". Jurnal 
Sense Vol 2 | No 1 | Mei 2019

Komunikasi Massa Fakultas Ilmu Sosial dan Ilmu Politik Universitas Gadjahmada, 2015.

Prayoga, Cahyo. "Semiotika Dalam Film Senyap". Skripsi S1 Universitas Pembangunan Nasional Veteran Jawa Timur, 2015.

Widayat, Rahmanu. "Krobongan Ruang Sakral Rumah Tradisi Jawa." Jurnal Penelitain Universitas Petra, 2004

Dharma, Azis. "Patriarki dalam Citra Perempuan Jawa". Ekspresi Online. http://ekspresionline.com (diakses 4 Juni 2017).

Soesandireja. "Filosofi Rumah Tradisional Jawa". Wacana.co. http://wacana.co (diakses 26 Januari 2019). 